Session 1333

\title{
Innovative Approach to Curriculum Development in Electrical Power Distribution and Loading
}

\author{
Ilya Y. Grinberg, Jack L. Waintraub \\ State University of New York, College at Buffalo/New Jersey Center for Advanced \\ Technological Education
}

\section{Introduction}

The past three decades have witnessed a technological explosion in the fields of solid-state electronics, microprocessors, lasers, fiber optics, signal processing, fields that have come to dominate the technical interests of college faculty and students. Because of this significant shift to new technologies, the shortage of electrical engineers and technicians with adequate knowledge of industrial power distribution theory and practice has now reached a critical point. Electrical power distribution and loading as a specific learning module is a timely and essential part of the electrical and power systems curriculum.

The industrial power distribution system, as any engineering system, typically includes three stages of a life cycle. These stages are:

- Research And Design

- Construction, Assembly, Adjustment

- Maintenance

The member of an engineering team (engineer, technologist, and technician) is required to work in three typical situations superimposed with the above mentioned stages of the life cycle: where the work is planned in advance; where there is no advance planning; and where repairs are needed.

Since modern engineering systems are treated in systems categories, it is desirable to apply the systems approach to the curriculum development and teaching methodology ${ }^{1,2}$. An integrated modular approach is a powerful tool in providing concurrent learning, comprehensive understanding of instructions presented, and a demonstration of the effectiveness of an interdisciplinary approach.

Our approach to curriculum development is consistent with systems concepts ${ }^{3}$. These concepts are

- Functional Analysis

- Requirements Or Criteria

- Synthesis

- Testing

- Communication 
The first two concepts are reflected in the identification of competencies and their interrelations (scope and sequence). The next three concepts include the development of learning activities based on the predetermined competencies (synthesis), practical implementation of these activities in a team-oriented industrial/commercial type project (testing), and demonstration of the results through efficient and authentic written and oral presentations (communication).

\section{Functional Analysis}

The study of electrical power distribution is no longer a popular topic taught in majority of Engineering and Technology Programs, as pointed out earlier. However, the need for personnel with a working knowledge of these systems is in demand by many industrial, commercial, and institutional facilities. The New Jersey Center for Advanced Technological Education (NJCATE) has included the study of these topics in their model Mecomtronics Engineering Technology Program. Curriculum components were established through a need analysis with industry personnel participation.

Industry personnel from a mix of large, medium and small companies were surveyed to assess the skills their technicians need to have. In addition an on-the-job task analysis was conducted at fifteen sites representing a variety of industries. The data collected formed the basis for the development of a list of competencies, which established the necessary skill and knowledge components for building a curriculum that integrates the technical subject matter with the study of mathematics, science and English communication topics.

The Mecomtronics Engineering Technology is based on 250 competencies of which 150 are classified as technical and 100 are core competencies in the areas of mathematics, physics and English communications ${ }^{4}$. Included in the list of competencies are also employability skills. This forms the basis for the Associate Degree curriculum; however, the methodology for the development and delivery of the content is applicable to all levels of technical education. The modular approach lends the flexibility to address topics such as power distribution, as a unit of learning that can be integrated in a variety of learning modes. The topics addressed in the module entitled, Electrical Power Distribution and Loading were selected to introduce many electrical concepts as well as to develop specific skills and knowledge in this area.

\section{Curriculum Requirements}

The curriculum construct is based on several features that impact on the organization of the content and the delivery. The modular design allows for grouping of technical areas of study and presenting the material within a context that is industry based. It also provides a vehicle for presenting core knowledge in support of the technical material in a concurrent fashion; meaning that, mathematics, physics and communication are taught in support of the technical course with the linking of content through the module ${ }^{5}$.

The curriculum is activity based and centered on projects within each module. The competencies to be learned are well articulated at the beginning of each activity and the scope of knowledge and skill to be achieved is defined on a scale of four levels of competency; Introduce, Develop, Master and Reinforce. One of the important features of this curriculum is that it is spiral in nature. As the student advances in studies, the student "moves up" on the spiral, 
achieving more knowledge and skill in a particular area, hence, becomes more competent. The level of competency achieved through the activities is indicated in the Scope and Sequence of Learning Outcomes matrix that links the competencies with the modules and the courses in the different disciplines. It provides the sequence of delivery and the level of competency to be gained. This assures that the students will master the competencies as they progress through the program.

The Electrical Power Distribution and Loading module addresses many competencies at different levels. The table below is a sample of the module competencies with the level of learning as indicated.

Table 1

\begin{tabular}{|l|l|l|}
\hline \multicolumn{1}{|c|}{ Competencies } & \multicolumn{1}{|c|}{ Type } & \multicolumn{1}{c|}{ Level } \\
\hline $\begin{array}{l}\text { 4.7 Demonstrate knowledge of } \\
\text { electromagnetic principles, operation of } \\
\text { electromagnetic devices and their use in } \\
\text { systems. }\end{array}$ & Technical & Develop (D) \\
\hline $\begin{array}{l}4.10 \quad \text { Demonstrate knowledge of electric } \\
\text { safety devices--such as switches, fuses, } \\
\text { breakers, etc.-- and proper grounding } \\
\text { techniques. }\end{array}$ & Technical & Develop (D) \\
\hline $\begin{array}{l}\text { 4.11 Demonstrate knowledge of power } \\
\text { distribution systems; troubleshoot and } \\
\text { correct system malfunctions. }\end{array}$ & Technical & Introduce, Develop, \\
\hline $\begin{array}{l}\text { 8.2 Measure and interpret electrical } \\
\text { quantities as compared to calculated values } \\
\text { or manufacturer's specifications. }\end{array}$ & Technical & Master (I, D) \\
\hline $\begin{array}{l}\text { 13.1 Convey ideas and facts by } \\
\text { composing, revising and editing memoranda } \\
\text { and letters, reports, articles, proposals, and } \\
\text { essays. }\end{array}$ & Communication & Develop (D) \\
\hline $\begin{array}{l}14.22 \text { Apply and use the concepts and } \\
\text { operations of vectors to solve technical } \\
\text { problems. }\end{array}$ & Mathematics & Develop, master (D, M) \\
\hline $\begin{array}{l}\text { 15.22 Calculate the energy stored in a } \\
\text { system of capacitors. }\end{array}$ & Physics & Master (M) \\
\hline
\end{tabular}

The table above shows a sample of the scope (level) of learning and the integration of the technical and core subjects through linking of competencies. 


\section{Synthesis and Project Description}

The objectives of the module are to provide students with an understanding of the basic principles of industrial power distribution systems and to apply that knowledge in the context of an industry-related project.

At the completion of this module, students will be able to:

- Plan, design, analyze and propose a project

- Evaluate and analyze data

- Present ideas and facts in written and oral form

One of the critical parts of the curriculum design is to provide a realistic project for students to work in a team-oriented environment. Industrial context was selected after consultations with the members of Industrial Advisory Committee of the Technology Department of Buffalo State College. The Carbide/Graphite Group, the manufacturer of graphite electrode products and calcium carbide products proposed the following situation:

One of the processes during graphite manufacturing involves cutting raw carbon rods. The ends are cut off raw carbon rods before graphitizing takes place. This is accomplished with an end cut saw. Several motors and a small room are part of this machine station. Outdated motor controls and building systems must be upgraded as part of a project designed to improve the reliability and performance of this machine station.

Your team must design a new power distribution system to support the needs of the saw motors and related equipment. The system will consist of a 480-Volt feeder and motor control center. A step-down transformer will be provided to supply 120 -Volt convenience outlets and general lighting to the area.

Students were provided with the company profile and the link to their home page was made available for further familiarization with the company's operations. The site plan of the facility and the floor plan of the building housing the end cut saw station were also provided.

Students were charged with the following task:

- Design power distribution system configuration

- Select, size and specify required power distribution equipment

- Size and specify required power distribution conduit and cable

- Size and specify heat tracing cable

- Produce equipment installation layout drawings

- Develop project manual and present a project report

\section{Learning Activities}

In order to achieve the objectives of the module, the predetermined competencies were grouped into learning activities based on the logic of typical design procedures. The learning activities were structured in a uniform way throughout the curriculum.

Table 2 represents technical learning activities and selected competencies associated with them. 
Note the designation of activities: $\mathbf{J}$ stands for the module number in the curriculum, PT stands for technical activities, SS stands for physics activities, SM stands for mathematical activities, and CS stands for communication and presentation activities.

Activities are designed as project embedded and project independent (stand-alone).

Table 2

\begin{tabular}{|c|c|}
\hline Learning Activity & Selected Competencies \\
\hline $\begin{array}{l}\text { JPT1. Electrical Symbols, } \\
\text { Construction Plans, and Site } \\
\text { Plans }\end{array}$ & $\begin{array}{l}3.7 \text { (R) Identify and create electrical and logic diagrams } \\
\text { utilizing a library of appropriate symbols } \\
3.12 \text { (D) Read and interpret engineering drawings, wiring } \\
\text { diagrams, schematics and process diagrams }\end{array}$ \\
\hline JPT2. Unit Substation & $\begin{array}{l}\text { 4.4 (R) Construct an AC or DC circuit from a wiring } \\
\text { diagram and predict and measure the currents through } \\
\text { and voltages across the circuit elements, and their power } \\
\text { used by the circuit (Ohm's Law, Kirchoff's Laws, } \\
\text { phasors, complex numbers) }\end{array}$ \\
\hline JPT 3. Feeder System & $\begin{array}{l}4.2(\mathrm{R}) \text { Apply Ohm's and Kirchoff's Laws to the analysis } \\
\text { of passive devices, their physical and electrical } \\
\text { characteristics, and their use in electrical systems }\end{array}$ \\
\hline $\begin{array}{l}\text { JPT4. Power Distribution } \\
\text { Systems: Configuration, } \\
\text { Design, and Analysis }\end{array}$ & $\begin{array}{l}\text { 4.4 (R) Construct an AC or DC circuit from a wiring } \\
\text { diagram and predict and measure the currents through } \\
\text { and voltages across the circuit elements, and their power } \\
\text { used by the circuit (Ohm's Law, Kirchoff's Laws, } \\
\text { phasors, complex numbers) } \\
4.12 \text { (I, D) Analyze balanced 3-phase networks }\end{array}$ \\
\hline $\begin{array}{l}\text { JPT5. Metering and } \\
\text { Measurements }\end{array}$ & $\begin{array}{l}7.7 \text { (D) Evaluate the measurements specification and } \\
\text { select the appropriate instrument to accurately perform } \\
\text { the measurement } \\
7.10 \text { (D) Evaluate and analyze data obtained from } \\
\text { measurements }\end{array}$ \\
\hline $\begin{array}{l}\text { JPT6. DC Starters and Speed } \\
\text { Controllers }\end{array}$ & $\begin{array}{l}4.13 \text { (D) Demonstrate knowledge of discrete } \\
\text { semiconductor devices, their characteristics and their use } \\
\text { in amplifier and switching applications } \\
4.23 \text { (D) Use engineering applications software for } \\
\text { electrical /electronics network and systems analysis and } \\
\text { simulation }\end{array}$ \\
\hline $\begin{array}{l}\text { JSS1. Thermodynamics } \\
\text { Principles }\end{array}$ & $\begin{array}{l}\text { 15.6R Apply thermodynamic concepts to predict the rate } \\
\text { of heat transfer through a system (conduction, } \\
\text { convection, and radiation) }\end{array}$ \\
\hline JSS2. Capacitor and Inductors & $\begin{array}{l}\text { 15.23R Predict and measure the capacitive time constant } \\
\text { of a RC circuit }\end{array}$ \\
\hline JSS3. AC Power and Resonance & $\begin{array}{l}\text { 15.25D Measure current as a function of frequency and } \\
\text { calculate the resonance frequency of an AC circuit }\end{array}$ \\
\hline JSS4. Magnetic Fields and & 15.50D Utilize Lenz's Law to explain the functioning \\
\hline
\end{tabular}




\begin{tabular}{|l|l|}
\hline Devices & motors, generators, and transformers \\
\hline JSM1. Geometric Figures & $\begin{array}{l}14.19 \text { (D) Apply trigonometric principles to the solutions } \\
\text { of technical problems using sine, cosine, and tangent } \\
\text { functions along with the law of sines and cosines }\end{array}$ \\
\hline JSM2. Systems of Equations & $\begin{array}{l}\text { 14.3(D) Estimate and approximate answers to multiple- } \\
\text { operation problems, and evaluate the reasonableness of } \\
\text { the results }\end{array}$ \\
\hline JSM3. Special Functions & $\begin{array}{l}\text { 14.13(D) Graph empirical data and determine the } \\
\text { function that the graph represents } \\
14.20 \text { (D) Apply exponential and logarithmic principles } \\
\text { to solve exponential and logarithmic equations } \\
\text { 14.28(D) Collect, organize and describe data from real- } \\
\text { world situations }\end{array}$ \\
\hline $\begin{array}{l}\text { JSM4. Mathematical Modeling } \\
\text { of Work and Force }\end{array}$ & $\begin{array}{l}\text { 14.27(D) Analyze collected data and use probability and } \\
\text { statistical models to make decisions about technical } \\
\text { situations } \\
14.28 \text { (D) Collect, organize and describe data from real- } \\
\text { world situations }\end{array}$ \\
\hline JCS1. Draft outline for progress \\
report & $\begin{array}{l}\text { 13.1D Convey ideas and facts by composing, revising } \\
\text { and editing memoranda and letters, articles, proposals } \\
\text { and essays } \\
\text { 13.3D Determine the form, length, content and style } \\
\text { either oral or written - for presenting materials to } \\
\text { intended audience }\end{array}$ \\
\hline JCS3. Oral Presentation & $\begin{array}{l}\text { 13.5D Annotate, summarize, paraphrase and use direct } \\
\text { quotations from reference materials, literature, reports, } \\
\text { articles, speeches and discussions } \\
\text { 13.10D Classify information into related groups, analyze } \\
\text { data to discover or present similarities and differences, to } \\
\text { discover or present relationships, to explain unfamiliar } \\
\text { concepts and to highlight specific details }\end{array}$ \\
$\begin{array}{l}\text { 13.2D Use varied and precise technical language } \\
\text { appropriately in written documents and oral presentations } \\
13.7 D \text { Gather and evaluate data obtained by searching } \\
\text { public access catalogs, on line and computer databases, } \\
\text { government documents, microfilms, and by conducting } \\
\text { field research and interviews }\end{array}$ \\
\hline Progress Report
\end{tabular}

The following is a brief overview of the activities provided for the Module J.

JPT1: Electric Symbols, Construction Plans and Site Plans

The purpose of this activity is to:

- Read and interpret electrical symbols used in construction drawings.

- Identify and discuss the electrical installation requirements for end cut saw project 
- Read site plans to determine the location of the specific items

The objectives of this learning activity are to identify and use electric symbols for the end-cut saw project and to read and understand floor plans and site plans for the end cut saw project. Necessary background information is presented in the form of a lecture highlighting the terminology of the plans and symbols. Students are required to use computer-aided drafting software to create and print a library of electrical symbols used in the construction plans. They are also asked to determine the lowest area of the site plan, determine elevation, the length of the footprint of the industrial building, and identify the preferred location of the construction trailer.

Students are assessed on the following:

- Ability to use computer-aided design software

- Ability to demonstrate knowledge of the task procedures

- Performance as a team member

- Ability to read architectural and electrical drawings and draw valid conclusions

\section{JPT2: Unit Substation}

The purpose of this activity is to:

- Determine electric load demand of an installation or system

- Define the functions of the components of a unit substation

- Select the proper size of a high-voltage fuse

The objectives of this learning activity are to:

- Determine load demand of newly installed end-cut saw machine station equipment

- Select standard high-voltage fuses to protect transformers discussed in the project

The background information is presented in the form of a class discussion concentrating on principles of electric demand calculations followed by transformer parameters determination, and transformer fuse selection procedures based on the requirements of the National Electrical Code (NEC@). The results of these calculations are used in sizing the feeder from the substation to the panelboard as well as in the analysis and optimization of the power distribution system for the end-cut saw motor installation.

Students are assessed on the following:

- Ability to demonstrate knowledge of the task procedures

- Ability to select proper formulas from the instructional material

- Ability to systematize and categorize information

- Performance as a team member

- Ability to read and understand procedures from the National Electrical Code (NEC®).

\section{JPT3: Feeder System}

This activity deals with a selection of conductors from the proper wire table of the NEC®, as well as the correction factors to determine the proper ampacity ratings of conductors. Topics such as conductor material, insulation type, and correction factors are presented. The cases of more than three conductors in raceway, underground conductors, and parallel conductors are covered. 
Students select the feeder system for the conductors between the substation and the machine station, as well as between the machine station panel and individual loads.

Students are assessed by the demonstration of knowledge of the task procedures, ability to select and use proper formulas from the instructional material, ability to organize and categorize information, and ability to read and understand procedures from the NEC@.

\section{JPT4: Power Distribution Systems: Configuration, Design, and Analysis}

The purpose of this activity is to:

- Select a proper configuration of a power distribution system

- Analyze a three-phase electric power system

- Determine electric parameters of system's elements

- Improve system's power factor

- Determine a voltage drop on a simple radial feeder

The objectives of this activity are to:

- Configure power distribution system for end cut saw machine station

- Represent a power distribution system as a simple electric circuit and identify its parameters and characteristics

- Select and place capacitors for power factor correction

- Verify the voltage levels of the system

The background information presents a variety of basic circuit arrangements available for industrial power distribution systems, such as simple radial system and secondary selective system. The discussion continues with an introduction to a balanced three-phase system and determination of a three-phase system's parameters: voltage, current, and power. Power factor correction and voltage drop are introduced.

Working on the project, the students use the site plan and the floor plan to identify the location of the unit substation, select a location of a panelboard inside the machine station, and identify the location of power consuming apparatus for the end-cut saw machine station. Based on this information the students select configuration of the power distribution system for the project and draw one-line diagram of the power system.

The drawing of the feeder lines is produced and the actual distances of feeder lines are determined. It is important to emphasize that developing of the one-line diagram is done concurrently with the drawings on the plan. That is, configuration of the system shown on the one-line diagram is reflected on the plans, as well as data determined from the plans (distances) is reflected on the one-line diagram.

During the next step the system is represented as a simple electric circuit and the resistance and reactance of each element are determined. Current, voltage, and the power factor of the system are calculated.

The following step deals with power factor correction. The students determine the size of capacitor, current through the feeder line and voltage at the panelboard before and after installing 
the capacitor. Voltage drop at the end of the feeder line is calculated and the system is checked for the permissible voltage levels.

Students are assessed on the following:

- Ability to read electric diagrams and impedance diagrams

- Ability to distinguish power distribution system's configuration

- Ability to analyze three-phase electric circuits

- Ability to demonstrate knowledge of the task procedures

- Performance as a team member

\section{JPT5: Metering and Measurements}

The purpose of this activity is to distinguish between instruments and meters and to be familiar with their varieties, as well as to identify functions of current and potential transformers.

The objectives of this activity are to:

- Calculate real and reactive power based on the kilowatt-hour and kilovar-hour meter readings

- Understand and utilize placement of instruments and meters in electrical installations for endcut saw machine station

The background information on instruments, meters, and their classes of accuracy is presented. Current and potential transformers are introduced.

Working on the project students determine the nomenclature of metering equipment to be placed for the end-cut saw machine station, size instrument transformers, and identify the placement of the instrument transformers and meters on the one-line diagram of the system.

Students are assessed on the following:

- Demonstration of knowledge of the task procedures

- Performance as a team member

\section{JPT6: DC Starters and Speed Controllers}

The purpose of this activity is to:

- Explain the operation of solid state relays

- Describe the functions of motor soft starters

- Explain the principle of operation of solid state dc motor speed controllers

The objectives of this activity are to:

- Understand the operation of solid state relays used in motor-drive circuits

- Understand, design, simulate, and troubleshoot DC motor drive circuit

The topic is linked to the project by introducing a DC motor drive of a dust collector installation in the machine station. The background information on silicon-controlled rectifiers (SCR) is provided as well as the principles of solid state control, DC starters and speed controllers, and triggering the SCR. 
During the project the students construct a circuit diagram of a solid-state DC motor drive using Electronics Workbench @ simulation software. The students activate the circuit and vary the value of the rheostat resistance from minimum to maximum and observe the waveforms. The students are assessed on the following:

- Ability to demonstrate knowledge of the task procedures

- Ability to work with circuit simulation software

- Performance as a team member

- Ability to read, understand, and troubleshoot electronic circuits

\section{Integrating Mathematics and Physics with Technical Activities}

It is important to make mathematics and physics activities (which are project independent) relevant to technical activities (project embedded). That was achieved through different strategies. For example, to relate the physics activity JSS3 AC Power and Resonance, it was decided to link it to the technical activities of the project by a memo form a design group to a research group. This memo states the situation of the necessity of installation of the power factor correction capacitors and requests analytical calculations and experiments to assure that this installation would not cause a problem of a parallel resonance. If it would, recommendations to avoid the potential problem should be made. In this case the link is provided by the use of written communication (memo). Obviously, this physics activity should be scheduled so that it would follow the corresponding technical activity (JPT4).

Another example is how to make the activity JSS1 Thermodynamics Principles relevant to the project. This was achieved by introducing the following situation:

Carbide/Graphite Group Inc. (CGI) is concerned about heat transfer from its new end-cut saw. It is desirable to cut the carbon rods as fast as possible, but if the cutting process is too fast, then the saw blade and the carbon rods may be damaged due to overheating. Since the heat is transmitted by conduction away from the saw blade, a simple calculation of heat transfer will resolve the matter. The results of this calculation would be used to select a proper cooling pump and a motor to drive it.

\section{Conclusion}

During our development of technical topics in Electrical Distribution and Loading, we utilized the compact language of mathematics, in conjunction with standard written English, to express the principles of physics that govern the behavior of electrical power systems. This combination of disciplines became possible due to the modular structure of the curriculum.

The project-driven curriculum combines activities that are both stand-alone and project embedded with a team approach. The required disciplinary knowledge is conveyed through contextualized, real-world linked activities. For example, local industrial/commercial field projects are used. Problem-finding and problem-solving strategies are embedded through these contextualized projects. 
The four main strands of the module, mathematics, physics, technical discipline and English communication are woven together to form an integrated, inter-dependent curriculum that challenges students to develop global critical thinking skills as well as hands-on experience while working through local and specific projects. Other NJCATE modules developed by interdisciplinary faculty teams from around the country have been pilot-tested in a variety of technical and core courses.

\section{Acknowledgements}

The NJCATE project is funded in part by the NSF Advanced Technological Education Program.

Bibliography

1.Grinberg, I., and Stratton, J. “A Systems Engineering Approach to Engineering Design Methodology.” Journal of Engineering Technology 13, No 2 (Fall 1996): 8- 13

2. Panitz, B. "Training Technology's Maestros." ASEE Prism, Volume 7, No 3 (November 1997), pp.18-24

3. Brian W. Mar, "Systems Engineering Basics", System Engineering, The Journal of the National Council on Systems Engineering, July / September 1994, pp. 7-15.

4. New Jersey Center for Advanced Technological Education (NJCATE). 1997. Mecomtronics Engineering

Technology: Scope and Sequence of Learning Outcomes. Edison, NJ: New Jersey Center for Advanced

Technological Education.

5. The College of New Jersey. 1998. The Magazine of Design \& Technology Education. January/February. Ewing, NJ: The College of New Jersey.

\section{ILYA Y. GRINBERG}

Ilya Grinberg graduated from the Lvov Polytechnic Institute (Lvov, Ukraine) with an MS in EE and earned a Ph.D. degree from the Moscow Institute of Civil Engineering (Moscow, Russia) with a specialization in systems engineering and design automation. He has 25 years of experience in design and consulting in the field of power distribution systems and design automation. Currently he is an associate professor of Engineering Technology at the State University of New York College at Buffalo. He is a Senior Member of IEEE, and a member of ASEE. His interests are in the field of power distribution systems, computerized design, and systems engineering.

JACK L. WAINTRAUB

Jack L. Waintraub is Professor and Chairman of the Physics/Electrical Engineering Technology Department at Middlesex County College, Edison, NJ. He currently, also serves as the Director of the New Jersey Center for Advanced Technological Education. He received his A.A.S. degree in Electronics Technology from the College of Aeronautics, the BS in EE from Polytechnic University and the MS in EE from Rutgers University. He is a Licensed Professional Engineer in the State of New Jersey and the author of several textbooks in Electrical Engineering Technology. In the past, he chaired the Electrical Engineering Technology Department Heads Association, was a member of the Education Activities Board of IEEE and served as a Program Director at the NSF during 1993-1994 in the Division of Undergraduate Education. He serves as TAC/ABET Commissioner and as member of the Committee on Technology Accreditation Activities of the IEEE. He is a Senior Member of IEEE and a member of ASEE. 